https://doi.org/10.48009/2_iis_2005_279-288

\title{
USER ACCEPTANCE OF DIGITAL LIBRARY: AN EMPIRICAL EXPLORATION OF INDIVIDUAL AND SYSTEM COMPONENTS
}

\author{
Ganesh Vaidyanathan, Indiana University South Bend, gvaidyan@iusb.edu \\ Asghar Sabbaghi, Indiana University South Bend, sabbaghi@iusb.edu \\ Michael Bargellini, Indiana University South Bend, mbargell@iusb.edu
}

\begin{abstract}
Potential users of digital libraries may not use the systems in spite of digitization efforts being popular. There is a need to understand the users' perspective and their acceptance of digital libraries. We use the technology acceptance model as a theoretical basis to understand individual acceptance of users. In this study, five individual and system components are used to explore individual user acceptance of a digital library. We find that antecedents such as search function, screen design, navigation and system reliability have significant effects on perceived ease-of-use and perceived usefulness which in turn have a significant effect on individual user acceptance.
\end{abstract}

Keywords: digital library, user acceptance, individual, system, components

\section{INTRODUCTION}

Digital libraries have received great attention in research and practitioner literature $[15,21,22]$. Digital libraries are electronic collections that are much richer in content and more capable in functionality than databases or information retrieval systems [2] and are increasingly accessible over the Internet. The major advantages of digital libraries include storing resources in an easyto-track digital format; allowing remote, rapid, and fair access to digital library collections, and providing search techniques that offer users increased flexibility and power [18]. As digital libraries are increasingly becoming popular, there exists a necessity to identify factors that can increase user acceptance of digital libraries. Such a model of digital library user acceptance based on the technology acceptance model was created [4]. In that study, the factors leading to user acceptance are terminology, screen design, navigation, relevance, system accessibility, system visibility, computer self-efficacy, computer experience, and domain knowledge.

Building a digital library is expensive and resource-intensive. As in the case of building any information system, the principles of building digital libraries are the same to include expect change, know your content, involve the right people, design usable systems, ensure open access, be aware of data rights, automate whenever possible, adopt and adhere to standards, ensure quality, and be concerned about persistence [12]. The growth and impact of digital libraries has raised several questions. The two major questions being asked are what precisely a digital library is, and what factors impact user acceptance of the digital library. This study will discuss which factors affect individual acceptance of a digital library. For the purposes of this study, we define digital library as digitization of traditional library resources. A recent study [7] used individual differences and system characteristics as factors that impact user acceptance. However, the model does not consider reliability that encompasses the speed of the system, system support, security, and confidence in using the system. System reliability has been used as a construct $[14,5,6,17]$ while analyzing many information systems. We propose a user acceptance model 
based on technology acceptance model (TAM) with some of the constructs used in previous models $[7,12,14,5,6,15,13]$. Our research includes system reliability as one of the constructs to evaluate the user acceptance of digital library.

\section{THEORY AND FRAMEWORK}

The decision to use the technology acceptance model was based on it being easier to apply and it having a slight empirical advantage [11]. The crucial point of the technology acceptance model is that adoption behavior is determined by individual acceptance and that is determined by perceived ease of use and perceived usefulness. Perceived ease of use and perceived usefulness are then determined by external variables that vary depending on the specific technology being studied. One key benefit of using TAM to understand system usage behavior is that it provides a framework to investigate the effects of external variables on system usage [7]. The key is to identify those external variables in order to achieve a successful implementation of a new technology; in this case, a digital library. It should also be noted that a digital library is a much broader concept then traditional IT, which lends itself to the use of the technology acceptance model over the other choices [7].

\section{Conceptual Framework}

The model used in this study as shown in Figure 1 varies from the basic technology acceptance model in several ways. The variations of the model are the external variables, which have an effect on the perceived ease of use and perceived usefulness of the digital library.

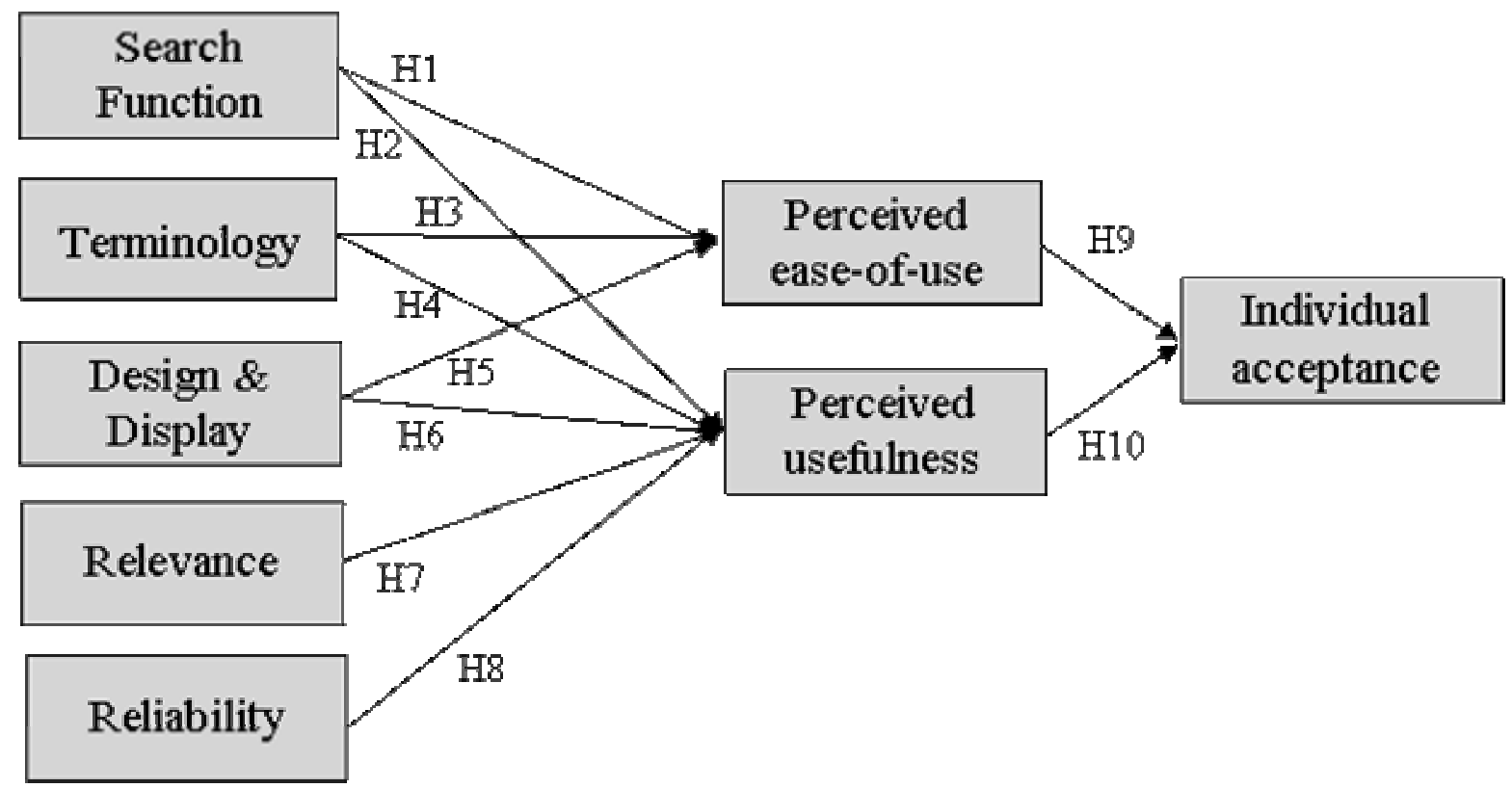

Figure 1. Conceptual Framework of Digital Library User acceptance

\section{Search Function}

The search function construct melds two different ideas. Past models have tended to focus on computer self-efficacy, which is the ability of a person to use a computer [3]. In the case of a 
digital library, which can encompass many complex systems working together, more specific skills are necessary for the user to succeed with the system. The key ingredient for successful use of a digital library may well be the user's expertise with search functions. Users need to possess the knowledge of the topic being searched. The more knowledge a user has about the topic, the more successful their search will be. However, the ability of a user is often overlooked as part of the search function. Being comfortable searching through a database, whether a user is just using basic commands or advanced techniques, is of vital importance in the success of the search. The ability of a user to use a search function as well as being knowledgeable in the search topic leads to the following hypotheses:

H1: Knowledge of topic and how to use the search function will have a positive impact on perceived ease of use.

H2: Knowledge of topic and how to use the search function will have a positive impact on perceived usefulness.

\section{Terminology}

Terminology refers to the words, sentences, and abbreviations used by the system [10]. The terminology variable can be described as language. For this particular variable, a user needs to be able to understand that specific language in order to accept and use the technology. Thus, based on past models, we have the following two hypotheses for this construct:

\section{H3: Understanding and consistency of terminology will have a positive impact on perceived usefulness. \\ H4: Understanding and consistency of terminology will have a positive impact on perceived ease of use.}

\section{Design \& Display}

This construct has been widely supported in various papers that the design of the screen and the display of information have a tremendous influence on the user's satisfaction with the system [8, $9,16]$. Users are more apt to be satisfied with the system if the design and display of information is presented in an organized manner and makes it as easy as possible for the user to both navigate the system and quickly retrieve the desired information. Therefore, our hypotheses for this external variable are as follows:

H5: Design and display will have a positive impact on perceived usefulness.

H6: Design and display will have a positive impact on perceived ease of use.

\section{Relevance}

Relevance pertains to the success of the system in returning the desired information that has been queried by the end user [10]. Put more simply, it is the degree to which the system, in this case, the digital library, successfully provides the user with the information they are requesting. A common example of relevance is the list of search results a user gets when utilizing a search engine. When a user is requesting information from the library, the items provided to the user must be meaningful in order for the user to feel successful in their search. We have the following hypothesis: 
H7: System relevance will have a positive impact on perceived usefulness.

\section{Reliability}

This construct measures the system quality as well as user confidence, response time, system support, and security. These factors are both common and important among various technical systems and a digital library is no different. The integrity of the actual files, users' comfort and confidence in the system, security, and fast response time belong to this construct. Therefore,

H8: System reliability will have a positive impact on perceived usefulness.

\section{RESEARCH METHODOLOGY AND EMPERICAL ANALYSIS}

The target audience for this project was both faculty and students at Indiana University, South Bend. We used two different methods to distribute the survey. A survey was passed in classes where taking the survey was optional and anonymous and took roughly ten minutes with this method. The other method used for distribution was a mass mail where the mailing simply directed the recipient to a website that contained the survey. Combined, the two methods yielded slightly 189 responses which amounted to about $45 \%$ response rate. A Likert scale with 7 being "strongly agree" and 1 being "strongly disagree" was used. In order to measure the model and the survey results, we used a Pearson correlation analysis.

Table 1. Construct Correlations

\begin{tabular}{lccc} 
& Ease of use & Usefulness & User Acceptance \\
\hline Search & .775 & .719 & .638 \\
Terminology & .666 & .654 & .528 \\
Design \& Display & .808 & .719 & .606 \\
Relevance & .688 & .593 & .590 \\
Reliability & .782 & .710 & .621 \\
Ease of Use & & & .736 \\
Usefulness & & & .842
\end{tabular}

From the correlation table as shown above, the first significant finding is the reinforcement of the significant positive relationship between the design and display construct and the perceived ease of use construct. This analysis also supports our theory by showing a significant relationship between the search function and perceived ease of use. Interestingly enough, the table also shows a strong positive relationship between reliability and perceived ease of use. The table indicates a strong relationship between search function, design and display, and reliability with perceived usefulness. Finally, this analysis continues to support both hypotheses and past studies that both perceived ease of use and perceived usefulness have a strong relationship with individual acceptance.

In the regression model, both perceived ease of use (beta=.238) and perceived usefulness (beta $=.663$ ) have a positive impact on individual acceptance. The analysis is also intriguing because the variables leading into perceived ease of use and perceived usefulness revealed some significant findings. In fact, the results of this analysis supported the results from the correlation analysis. Both search function (beta=.398) and design and display (beta=.540) are shown to have 
a strong positive impact on perceived ease of use. Likewise, search function (beta=.307), design and display (beta $=.193)$, and reliability (beta $=.210$ ) have a strong positive impact on perceived usefulness. The survey results support our hypotheses H1, H2, H5, H6, H8, H9, and H10.

Table 2. Regression Analysis

\begin{tabular}{|c|c|c|c|c|c|}
\hline & Beta & T-Value & $\mathbf{R}^{2}$ & Mean & $\begin{array}{l}\text { Standard } \\
\text { Deviation }\end{array}$ \\
\hline Perceived ease of use $=$ & & & 0.709 & & \\
\hline Search function + & 0.398 & 5.602 & & 5.8862 & 0.91489 \\
\hline Terminology + & -0.054 & -0.791 & & 5.9630 & 0.93325 \\
\hline Design \& Display & 0.540 & 7.910 & & 6.2177 & 0.92729 \\
\hline Perceived usefulness $=$ & & & 0.600 & & \\
\hline Search function + & 0.307 & 3.543 & & 5.8862 & 0.91489 \\
\hline Terminology + & 0.074 & 0.915 & & 5.9630 & 0.93325 \\
\hline Design \& Display + & 0.193 & 1.849 & & 6.2177 & 0.92729 \\
\hline Relevance + & 0.073 & 1.070 & & 5.5591 & 1.05334 \\
\hline Reliability & 0.210 & 2.139 & & 6.1019 & 0.98182 \\
\hline Individual Acceptance $=$ & & & 0.733 & & \\
\hline Perceived ease of use + & 0.238 & 4.139 & & 5.8995 & 0.98043 \\
\hline Perceived usefulness & 0.663 & 11.552 & & 5.8757 & 1.07456 \\
\hline
\end{tabular}

DISCUSSION

While the backbone of TAM is that perceived ease of use and perceived usefulness affect individual acceptance, it is the variables that lead to these two constructs that drive the model. In this study, we have introduced the reliability variable. The results of the study are consistent with past uses of the technology acceptance model in that the data supports the accepted notion that perceived ease of use and perceived usefulness have a strong positive impact on individual acceptance. There is continuing debate over which of these is actually more influential [1, 7]. As shown in Tables 1 and 2, this study shows that perceived usefulness is significantly more important in determining individual acceptance then perceived ease of use. Looking at these two constructs makes it easier to understand why perceived usefulness would be more important to individual acceptance then perceived ease of use. Search function construct clearly supports hypotheses $\mathrm{H} 1$ \& $\mathrm{H} 2$ and illustrate that knowledge of the search topic and how to use the search function will have a positive impact on both perceived ease of use and perceived usefulness. Due to the complex nature of a digital library, we argue that the key ingredient in individual acceptance could very well be this specific construct. This is because of the effect that this construct has on both perceived ease of use and perceived usefulness. While other constructs may have a higher effect on one, it is the search function that has the highest effect on both perceived ease of use and perceived usefulness as the regression model suggests with beta of 0.398 and 0.307 . This study supports our theory that individuals that are knowledgeable on the topic they are researching and know how to use that particular search function are more likely to accept the digital library. 
As far as the terminology construct, the study failed to support either of the hypotheses $\mathrm{H} 3$ and H4. While the correlation analysis showed some mild support for each of these hypotheses, the regression analysis showed no support whatsoever. The terminology construct has been used in multiple TAM models for different computer applications and it remained consistent in our model. However, the results do not show that a user's understanding of the terminology used by the digital library will have a positive impact on individual acceptance. Our results did support both hypotheses H5 and H6 regarding the design and display construct. Clearly, the presentation of the system is the most important thing to a user when determining perceived ease of use. Further evidence of user beliefs and attitudes being key perceptions driving information technology usage is shown in a recent study [23]. Similar to the terminology construct, our results did not show much, if any, support for hypothesis $\mathrm{H} 7$ that system relevance will have a positive impact on perceived usefulness. However, the relevance of what a digital library supplies to an individual user is complex as there are many ways the users employ the criteria in making their own evaluations of relevance. While the analysis supported the hypothesis H8 that the reliability of the system would have a positive impact on perceived usefulness, we see the additional support the results showed for reliability having a positive impact on perceived ease of use.

\section{CONCLUSION}

Overall, this study succeeded in showing several points. The first was the correct assumption in applying the technology acceptance model when determining individual user acceptance of digital libraries. Perceived ease of use and perceived usefulness both showed a significant positive impact on individual acceptance, the cornerstone of the technology acceptance model. A follow-up study running a comparison model with a better defined terminology construct as separate and as part of the search function construct would be intriguing and help to answer the questions that our results raised. The major concern in this study was the lack of support for a significant positive relationship between relevance and perceived ease of use. Finally, it can be difficult using a model that fits for past computer applications and modifying it for a new technology like digital libraries as some factors may be more important than others. For instance, some studies of TAM suggest that perceived usefulness is more important than perceived ease of use in determining whether to use a technology $[19,20]$. Despite some setbacks, we believe our model presents some good ideas and would be a good jumping off point for further studies in this area.

\section{REFERENCES}

1. Adams, D. A., Nelson, R. R. \& Todd, P. A. (1992). Perceived Usefulness, Ease of Use, and Usage of Information Technology: A replication, MIS Quarterly, (16), 227-247.

2. Borgman, C.L. (1999). What are digital libraries? Information Processing and Management, 35(3), 227-243.

3. Compeau, D. R. \& Higgins, C. A. (1995) Computer Self-efficacy: Development of a measure and initial test, MIS Quarterly, 19(2), 189-211.

4. Davis, F.D. (1989). Perceived usefulness, perceived ease of use, and user acceptance of information technology, MIS Quarterly, 13(3), 319-340.

5. DeLone, W.H. \& McLean, E. R. (1992) Information Systems Success: The Quest for the Dependent Variable, Information Systems Research, 3(1), 60-95. 
6. Hamilton, S. \& Chervany, N.I. (1981). Evaluating Information System Effectiveness Part 1 Comparing Evaluation Approaches, MIS Quarterly, 5(3), 55-69.

7. Hong, W., Thong, J.Y.L., Wong, W. \& Tam, K. (2002). Determinants of user acceptance of digital libraries: an empirical examination of individual differences and system characteristics, Journal of Management Information Systems, 18(3), 97-124.

8. Jarvenpaa, S. L. (1989). The effect of task demands and graphical format on information processing strategies, Management Science, 35(3), 285-303.

9. Lim, K. H., Benbasat, I. \& Todd, P. A. (1996). An experimental investigation of the interactive effects of interface style, instructions, and task familiarity on user performance, ACM Transactions on Computer-Human Interaction, 3(1), 1-37.

10. Lindgaard, G. (1994). Usability Testing and System Evaluation: A Guide for Designing Useful Computer Systems. London and New York: Chapman \& Hall.

11. Mathieson, K. (1991). Predicting User Intentions: Comparing the Technology Acceptance Model with the Theory of Planned Behavior, Information Systems Research, 2(3), 173-191.

12. McCray, A.T. \& Gallagher, M.E. (2001). Principles for digital library development, Communications of the ACM, 44(5), 48-54.

13. Park, S. (2000). Usability, user preferences, effectiveness, and user behaviors when searching individual and integrated full-text databases: Implications for digital libraries, Journal of the American Society for Information Science, 51(5), 456-468.

14. Swanson, E. B. (1974). Management Information Systems: Appreciation and Involvement, Management Science, 21(2), 178-188.

15. Thong, J.Y.L., Weiyin, H., Kar, Y.T. (2004). What leads to user acceptance of digital libraries? Communications of the ACM, 47(11), 79-83.

16. Todd, P.A. \& Benbasat, I. (1991). An experimental investigation of the impact of computer based decision aids on decision-making strategies, Information Systems Research, 2(2), 87115.

17. Walter, W.H. (2004). Criteria for Replacing Print Journals with Online Journal Resources: The Importance of Sustainable Access, Library Resources \& Technical Services, 48(4), 300304.

18. Wiederhold, G. (1995). Digital libraries, value, and productivity, Communications of the ACM, 38(4) 85-96.

19. Chau, P.Y.K. (1996). An empirical assessment of a modified technology acceptance model. Journal of Management Information Systems, 13(2), 185-204.

20. Venkatesh, V. (2000). Determinants of perceived ease of use: Integrating control, intrinsic motivation, and emotion into the technology acceptance model. Information Systems Research, 11(4), 342-365.

21. Koohang, A. \& Ondracek, J. (May 2005). Users' views about the usability of digital libraries. British Journal of Educational Technology, 36(3), 407-423.

22. Hutchinson, H.B., Rose, A., Bederson, B., Weeks, A. \& Druin, A. (2005). The International Children's Digital Library: A Case Study in Designing for a Multilingual, Multicultural, Multigenerational Audience. Information Technology \& Libraries, 24(1), 4-12.

23. Bhattacherjee, A. \& Premkumar, G. (2004). Understanding changes in belief and attitude toward information technology usage: A theoretical model and longitudinal test. MIS Quarterly, 28(2), 229-254. 